\title{
Definitive chemoradiotherapy versus radical hysterectomy followed by tailored adjuvant therapy in women with early- stage cervical cancer presenting with pelvic lymph node metastasis on pretreatment evaluation: A propensity score matching analysis
}

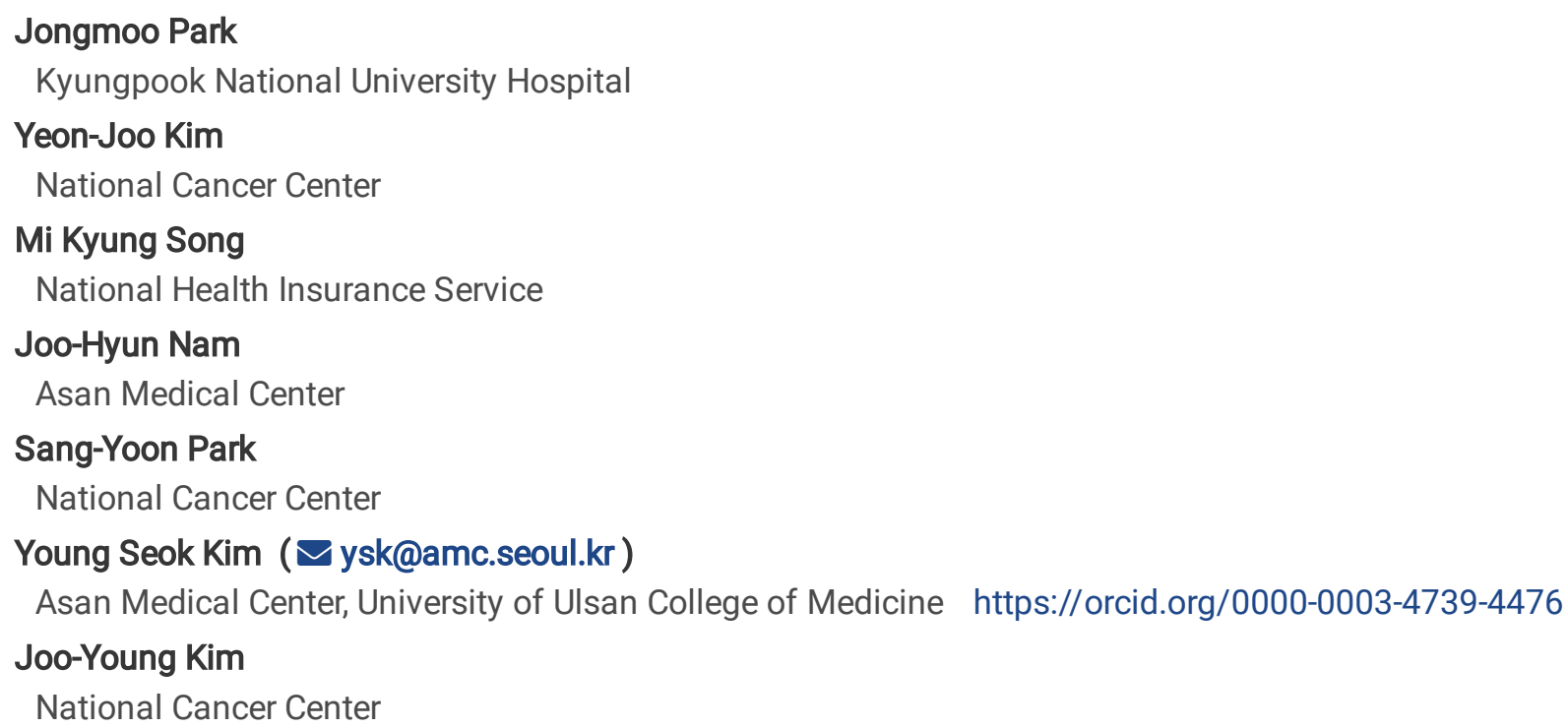

Research

Keywords: uterine cervical cancer, radiotherapy, chemotherapy, hysterectomy

Posted Date: March 25th, 2020

DOI: https://doi.org/10.21203/rs.3.rs-18899/v1

License: @) (1) This work is licensed under a Creative Commons Attribution 4.0 International License. Read Full License

Version of Record: A version of this preprint was published at Cancers on July 23rd, 2021. See the published version at https://doi.org/10.3390/cancers13153703. 


\section{Abstract}

Objective To compare the oncologic outcomes between chemoradiotherapy and radical hysterectomy followed by tailored adjuvant therapy in patients with early cervical cancer presenting with pelvic lymph node metastasis.

Methods We retrospectively analyzed the medical records of women with early cervical cancer presenting with positive pelvic nodes identified on pretreatment imaging assessment. Propensity score matching was employed to control for the heterogeneity between two groups according to confounding factors. Overall survival, disease-free survival, and pattern of failure were compared between the two groups in all patients as well as the matched cohort.

Results A total 262 patients were identified; among them, 67 received definitive chemoradiotherapy (group A) and 195 received hysterectomy (group B). Adjuvant therapy was administered to $88.7 \%$ of group B. There were no significant differences between group $A$ and group $B$ regarding the 5 -year overall survival rates ( $89.2 \%$ vs. $89.0 \%)$ as well as disease-free survival rates ( $80.6 \%$ vs. 82.7$)$ in the entire cohort, and patterns of failure. Distant metastasis was the major failure pattern identified in groups A and B (16.4\% and 15.4\%). In multivariate analysis, non-squamous histology was significantly associated with poorer overall survival.

Conclusion There were no significant differences in oncologic outcomes between definitive chemoradiotherapy and radical hysterectomy followed by tailored adjuvant therapy for early stage cervical cancer patients who had pelvic lymph node metastasis on pretreatment imaging assessment. Definitive chemoradiotherapy could avoid the complication of combined modality therapy without compromising oncologic outcomes.

\section{Background}

Definitive chemoradiotherapy and radical hysterectomy followed by tailored adjuvant therapy are both suitable treatment modalities in patients with early-stage cervical cancer [1]. Radical hysterectomy followed by adjuvant therapy is the preferred treatment strategy for early-stage cervical cancer patients, particularly for patients with a non-bulky tumor or for those who want to preserve the ovarian function [2]. Following surgery, adjuvant therapy is indicated in cases with pathological risk factors to improve the overall survival (OS) [3, 4]. Previous studies reported that $30-60 \%$ of patients required adjuvant therapy after surgery, which led to an increase in the risk of higher morbidity [4-6]. Definitive chemoradiotherapy is preferred for patients with a bulky tumor or for those in an inoperable condition, and it is particularly recommended for patients expected to require additional adjuvant therapy to avoid unplanned combined modality therapy, which increases the risk of treatmentrelated morbidity.

Pelvic nodal involvement is identified in more than $30 \%$ of early-stage cervical cancer patients on pretreatment imaging studies, such as magnetic resonance imaging (MRI) and positron emission tomography-Computed tomography (PET-CT) [7-

9]. The positive predictive value of these imaging studies was reportedly as high as $92 \%[10,11]$. However, there is currently no consensus regarding whether curative chemoradiotherapy or radical hysterectomy followed by adjuvant therapy would be more appropriate in these patients.

The aim of this study was to compare oncologic outcomes between women treated in two institutions with different policies; all women had early-stage cervical cancer with pelvic nodal involvement confirmed by pretreatment imaging.

Chemoradiotherapy was preferred at one institution for these patients, whereas radical hysterectomy was preferred at the other. The primary objective of this study was to compare OS, and the secondary endpoint was the pattern of failure between two groups.

\section{Methods}

Patients 
We analyzed the medical records of patients with histologically proven early-stage cervical cancer with pelvic nodal involvement detected by pretreatment imaging evaluation between 2001 and 2014 at two institutions. Patients who had invasive carcinoma with more than $5 \mathrm{~mm}$ depth of stromal invasion and involvement limited to the upper two-thirds of the vagina without parametrial involvement were enrolled; the inclusion was irrespective of the tumor size. Patients were excluded if they (i) were negative for pelvic nodal involvement on both pretreatment MRI and PET-CT, (ii) received neoadjuvant chemotherapy, (iii) had clinically confirmed para-aortic, inguinal, and/or supraclavicular lymph node involvement, (iv) had tumor histology other than squamous cell carcinoma, adenocarcinoma, or adenosquamous cell carcinoma, or (v) had other malignancies within the last 6 months. Initial imaging studies included MRI and PET-CT. This study was approved by the institutional review board of each participating center; informed consent was waived due to its retrospective nature.

\section{Treatment}

1) Definitive chemoradiotherapy

External beam radiotherapy of 45-50.4 Gy was delivered by the four-field technique using linear accelerators or by tomotherapy. Prophylactic extended field radiotherapy covering the PAN region was applied to the patients enrolled in the phase II trial.[12] An additional 10-20 Gy boost was given to the positive pelvic nodes $>1.5 \mathrm{~cm}$ in diameter at diagnosis, according to the institutional policy. High-dose-rate MRI-guided brachytherapy with median physical dose of $30 \mathrm{~Gy}$ in six fractions was delivered twice a week. MRI-guided brachytherapy procedures are described in greater detail elsewhere [13, 14]. MRI-guided brachytherapy was performed according to the recommendations of the GEC-ESTRO Working Group [15]. Weekly cisplatin was given concurrently with radiotherapy.

2) Upfront surgery followed by tailored adjuvant treatment

Hysterectomy was performed with the Piver-Rutledge type 2 or 3 combined pelvic lymphadenectomy using either laparotomy or laparoscopy. After the surgery, tailored adjuvant therapy was administered to the patients who had a high-risk pathologic factor or two or more of the intermediate-risk features. Adjuvant external beam radiotherapy was delivered to a total dose 46 Gy-50.4 Gy. Vaginal stump brachytherapy was considered for patients with positive or close vaginal margin after the completion of external radiotherapy. Two to four sessions of the high-dose-rate brachytherapy were delivered twice every week, with a fractional dose of 5-6 Gy using a ${ }^{192}$ Ir source. Platinum-based chemotherapy, mainly weekly cisplatin, was given concurrently with adjuvant radiotherapy to women with a high-risk pathologic feature.

After treatment, regular follow-up evaluations were performed at 1 month, at 3 month intervals for 2 years, and then every 6 months thereafter. Imaging studies, such as computed tomography (CT), MRI, or PET-CT, were done at least annually or when recurrence was suspected.

Statistical analysis

Local recurrence was defined as recurrence in the original tumor site, resection bed, or stump site; regional recurrence was defined as recurrence within the radiation or surgical field including pelvic cavity and regional node; and distant metastasis was defined as occurrence outside the radiation or surgical field or beyond pelvis, including para-aortic and supraclavicular node. The survivals were estimated from the date of the start of radiotherapy or surgery to the date of the last follow-up or an event of interest, such as death, any recurrence, or distant metastasis. Disease-free survival (DFS) was defined as the time until recurrence, distant metastasis, or death, whichever occurred first. The survival rates were estimated using the Kaplan-Meier method and were compared by log-rank test. Univariate and multivariable analyses were performed using the Cox proportional hazards model to determine the association of clinical factors with survival outcomes. Backward selection method was used to select the covariates to be included in multivariable models.

To control for the heterogeneity between two groups according to confounding variables of this retrospective, non-randomized study, propensity score matching (PSM) of groups A and B was conducted. Before PSM, to identify the variables that cause the difference in characteristics of the two groups, categorical and continuous variables were compared using Chi-square test or 
Fisher's exact test and Mann-Whitney U test, respectively. For propensity score estimation, a logistic regression model based on the following variables was used: age, histology, and vaginal invasion. Groups A and B were matched one-to-one by the propensity score obtained using the standard greedy matching algorithm. Model calibration procedures were performed $(p=$ $0.86)$, and the discriminating ability $(A \cup C=0.65)$ was confirmed. The best matching pair was selected in group $B$ for each one in group $A$ according to the absolute difference in propensity scores using the standard greedy matching algorithm to identify the closet match within a maximum distance of 0.07 . In consideration of the dependency after PSM, McNemar's test and Wilcoxon signed-rank test were used to compare between two groups according to the variable attributes, and the survival curves were compared using the stratified log-rank test for considering the dependency. Statistical analysis was performed using SAS, and R package, version 3.1.2.

\section{Results}

Out of 262 patients with positive pelvic node(s) detected on pretreatment imaging evaluations, 67 received curative chemoradiotherapy (group A), and 195 received surgery-based treatment (group B). Baseline patient and tumor characteristics before and after one-to-one PSM are shown in Table 1. In the entire cohort, there was no significant difference in terms of age, histology, and tumor size between groups A and B. Squamous cell carcinoma was the most common histologic type in both groups but was more common in group $A(91.0 \%$ vs. $78.5 \%, p=0.02)$. Vaginal invasion was significantly different between groups A and B (37.3\% vs. 15.4\%; $p<0.01)$. After PSM, the two groups obtained not only equal distribution of vaginal invasion but were also more balanced in other characteristics. 
Table 1

Patient characteristics before and after one to one propensity score matching.

\begin{tabular}{|c|c|c|c|c|c|c|c|c|c|c|c|}
\hline & & \multicolumn{5}{|c|}{ Entire cohort } & \multicolumn{5}{|c|}{ Propensity score matching cohort } \\
\hline & & \multicolumn{2}{|c|}{$\begin{array}{l}\text { Group } A(n= \\
67)\end{array}$} & \multicolumn{2}{|c|}{$\begin{array}{l}\text { Group } B(n= \\
195)\end{array}$} & \multirow[b]{2}{*}{$\mathrm{p}$} & \multicolumn{2}{|c|}{$\begin{array}{l}\text { Group A }(\mathrm{n}= \\
66)\end{array}$} & \multicolumn{2}{|c|}{$\begin{array}{l}\text { Group B }(\mathrm{n}= \\
66)\end{array}$} & \multirow[b]{2}{*}{$\mathrm{p}$} \\
\hline & & $\mathrm{n}$ & $(\%)$ & $\mathrm{n}$ & (\%) & & $\mathrm{n}$ & $(\%)$ & $\mathrm{n}$ & $(\%)$ & \\
\hline \multirow[t]{3}{*}{ Age } & $\begin{array}{l}\text { median, } \\
\text { year } \\
\text { (range) }\end{array}$ & 46.0 & $\begin{array}{l}(22.0 \\
87.0)\end{array}$ & 46.0 & $\begin{array}{l}(22.0 \\
-76.0)\end{array}$ & 0.195 & 45.5 & $\begin{array}{l}(22.0- \\
87.0)\end{array}$ & 46.0 & $\begin{array}{l}(22.0- \\
76.0)\end{array}$ & \\
\hline & $\leq$ & 36 & $(53.7)$ & 101 & $(51.8)$ & 0.784 & 36 & $(54.6)$ & 35 & $(53.0)$ & 0.564 \\
\hline & $\begin{array}{l}> \\
46 \text { year }\end{array}$ & 31 & $(46.3)$ & 94 & $(48.2)$ & & 30 & $(45.5)$ & 31 & $(47.0)$ & \\
\hline \multirow[t]{2}{*}{ Histology } & $\mathrm{scC}$ & 61 & $(91.0)$ & 153 & $(78.5)$ & 0.022 & 60 & $(90.9)$ & 61 & $(92.4)$ & 0.317 \\
\hline & $\begin{array}{l}\text { Non- } \\
\text { SCC }\end{array}$ & 6 & $(9.0)$ & 42 & $(21.6)$ & & 6 & $(9.1)$ & 5 & $(7.6)$ & \\
\hline \multirow[t]{3}{*}{$\begin{array}{l}\text { Tumor } \\
\text { size }^{*}\end{array}$} & $\begin{array}{l}\text { median, } \\
\text { cm } \\
\text { (range) }\end{array}$ & 4.1 & $\begin{array}{l}(1.5- \\
8.3)\end{array}$ & 4.0 & $\begin{array}{l}(0.2- \\
11.0)\end{array}$ & 0.867 & 4.1 & $\begin{array}{l}(1.5- \\
8.3)\end{array}$ & 4.0 & $\begin{array}{l}(1.0- \\
11.0)\end{array}$ & \\
\hline & $\leq$ & 30 & $(49.2)$ & 112 & $(58.0)$ & 0.225 & 28 & $(47.5)$ & 31 & $(52.5)$ & 0.532 \\
\hline & $>4.0 \mathrm{~cm}$ & 31 & $(50.8)$ & 81 & $(42.0)$ & & 31 & $(52.5)$ & 28 & $(47.5)$ & \\
\hline \multirow[t]{2}{*}{$\begin{array}{l}\text { Vaginal } \\
\text { invasion }\end{array}$} & Negative & 42 & $(62.7)$ & 165 & $(84.6)$ & $\dot{0} 001$ & 42 & $(63.6)$ & 42 & $(63.6)$ & $\overrightarrow{0} .999$ \\
\hline & Positive & 25 & (37.3) & 30 & $(15.4)$ & & 24 & $(36.4)$ & 24 & $(36.4)$ & \\
\hline SCC-Ag & $\begin{array}{l}\text { median, } \\
\text { (range) }\end{array}$ & 4.6 & $\begin{array}{l}(1.0- \\
36.3)\end{array}$ & 2.3 & $\begin{array}{l}(0.2 \\
-105.5)\end{array}$ & - & & & & & \\
\hline \multirow[t]{2}{*}{ RT field } & $\begin{array}{l}\text { Whole } \\
\text { pelvis }\end{array}$ & 45 & $(67.2)$ & 161 & $(82.6)$ & - & & & & & \\
\hline & $\begin{array}{l}\text { Whole } \\
\text { pelvis + } \\
\text { PAN }\end{array}$ & 22 & $(32.8)$ & 12 & $(6.1)$ & & & & & & \\
\hline \multicolumn{12}{|c|}{$\begin{array}{l}\text { Abbreviation: Group A, definitive chemoradiotherapy; Group B, up front radical hysterectomy followed by tailored adjuvant } \\
\text { therapy; n, number; SCC, squamous cell carcinoma; SCC-Ag, squamous cell carcinoma antigen; RT, radiation therapy; PAN, } \\
\text { para-aortic node. }\end{array}$} \\
\hline
\end{tabular}

In group A ( $n=67), 22$ patients were treated with extended-field radiotherapy. Fifty-nine patients were treated with concurrent chemotherapy with weekly cisplatin, and eight were treated with radiotherapy alone due to the poor performance status. In group B $(n=195)$, radical hysterectomy was performed for 189 , and simple hysterectomy or trachelectomy was performed for six women who wanted to preserve fertility or were in poor condition. Pelvic lymphadenectomy was performed in all patients except one patient, and para-aortic lymphadenectomy was combined in 58. Pathologic pelvic nodal metastasis was observed in 116 patients, and para-aortic nodal metastasis was observed in six. Adjuvant therapy was required in 173 patients: 145 were treated with adjuvant chemoradiotherapy, mainly weekly cisplatin regimen, and 28 treated with adjuvant radiotherapy alone, whereas 22 did not receive adjuvant therapy. Among the patients undergoing adjuvant radiotherapy alone or adjuvant 
chemoradiotherapy (total 173 patients), 12 (6.2\%) underwent extended-field radiotherapy encompassing the para-aortic lymph nodal area.

At the time of analysis, 29 patients had died and 233 patients were alive. The median follow-up was 62.2 months and 54.9 months for group $A$ and group B, respectively. The 5 -year OS rates were $89.0 \%$ for group A and $89.2 \%$ for group B (Fig. 1 A). The 5 -year DFS rates were $82.7 \%$ and $80.6 \%$ for group A and group B, respectively (Fig. 1B). Both univariate and multivariable analyses showed that treatment modality was not related to OS (Table 2). Non-squamous histology was shown to affect OS on univariate and multiple analyses (HR, 2.786; $95 \% \mathrm{Cl}, 1.269-6.116 ; \mathrm{p}=0.01)$, and it was also a significant prognostic factor for DFS on multiple analysis (HR, 3.47; $95 \% \mathrm{Cl}, 1.82-6.6 ; \mathrm{p}=0.01)$. Figure 2 presents the survival curves of the PSM cohort in both groups. The 5-year OS and DFS showed no significant differences between group A and group B. Recurrence was observed in 63 (24.0\%) patients (Table 3). Distant metastasis was the most common pattern of failure in both groups $A$ and $B$ (15.4\% vs. $16.4 \%)$. Regional recurrence was more commonly observed in group A (6.0\% vs. $2.1 \%)$ without statistical significance $(p=0.12)$.

Table 2

Univariate and multivariate analysis of factors for overall survival

\begin{tabular}{|c|c|c|c|c|c|c|c|c|}
\hline & & \multirow[b]{2}{*}{$\mathrm{n}$} & \multicolumn{3}{|c|}{ Univariate analysis } & \multicolumn{3}{|c|}{ Multivariate analysis } \\
\hline & & & $\mathrm{HR}$ & $(95 \% \mathrm{Cl})$ & $\mathrm{p}$ & $\mathrm{HR}$ & $(95 \% \mathrm{Cl})$ & $\mathrm{p}$ \\
\hline \multirow[t]{2}{*}{ Treatment modality } & Group A & 67 & & Reference & & & & \\
\hline & Group B & 195 & 0.934 & $(0.398-2.190)$ & 0.874 & 1.114 & $(0.467-2.658)$ & 0.808 \\
\hline \multirow[t]{2}{*}{ Age } & $\leq 46$ & 137 & & Reference & & & & \\
\hline & $>46$ & 125 & 0.811 & $(0.390-1.688)$ & 0.576 & & & \\
\hline \multirow[t]{2}{*}{ Histology } & SCC & 214 & & Reference & & & & \\
\hline & Non-SCC & 48 & 2.733 & $(1.265-5.903)$ & 0.011 & 2.786 & $(1.269-6.116)$ & 0.011 \\
\hline \multirow[t]{2}{*}{ Vaginal invasion } & Negative & 207 & & Reference & & & & \\
\hline & Positive & 55 & 1.463 & $(0.648-3.306)$ & 0.360 & & & \\
\hline \multirow[t]{2}{*}{ Tumor size * } & $\leq 4.0 \mathrm{~cm}$ & 142 & & Reference & & & & \\
\hline & $>4.0 \mathrm{~cm}$ & 112 & 1.012 & $(0.479-2.141)$ & 0.974 & & & \\
\hline \multicolumn{9}{|c|}{$\begin{array}{l}\text { Abbreviation: Group A, definitive chemoradiotherapy; Group B, up front radical hysterectomy followed by tailored adjuvant } \\
\text { therapy; n, number; HR, hazard ratio; Cl, confidence interval; SCC, squamous cell carcinoma; FIGO, International Federation } \\
\text { of Gynecology and Obstetrics. }\end{array}$} \\
\hline
\end{tabular}


Table 3

Patterns of failure

\begin{tabular}{|c|c|c|c|c|c|}
\hline & \multicolumn{2}{|c|}{ Group A $(n=67)$} & \multicolumn{2}{|c|}{ Group B $(n=195)$} & \multirow[b]{2}{*}{$\mathrm{p}$} \\
\hline & $\mathrm{n}$ & $(\%)$ & $\mathrm{n}$ & $(\%)$ & \\
\hline Local recurrence & 3 & $(4.5)$ & 11 & $(5.6)$ & $>0.999$ \\
\hline Regional recurrence & 4 & $(6.0)$ & 4 & $(2.1)$ & 0.119 \\
\hline Distant metastasis & 11 & $(16.4)$ & 30 & $(15.4)$ & 0.841 \\
\hline PAN & 6 & $(8.9)$ & 11 & $(5.6)$ & - \\
\hline SCL & 1 & $(1.5)$ & 4 & $(2.1)$ & - \\
\hline Other site & 6 & $(8.9)$ & 23 & $(11.8)$ & - \\
\hline
\end{tabular}

\section{Discussion}

This study demonstrates there was no significant difference in 5-year OS and DFS between the two treatment strategies before and after PSM. Moreover, there was no difference in patterns of failure. Notably, the majority (88.7\%) of women who underwent radical hysterectomy received adjuvant therapy. The results were in line with those of previous reports. A prospective randomized trial had showed radiotherapy and surgery to be equally effective as primary treatments for women with early cervical cancer [5]. Subsequent retrospective studies did not reveal significantly different survival outcomes between definitive chemoradiotherapy and hysterectomy followed by tailored adjuvant therapy in early cervical cancer $[6,16]$. More recently, a phase III, randomized controlled trial reported the surgical treatment after neoadjuvant chemotherapy does not improve oncologic outcomes compared with upfront chemoradiotherapy in early-stage cervical cancer patients [17]. However, among the patients who underwent surgery, 23-63\% required adjuvant radiotherapy or chemoradiotherapy $[5,16-18]$. Combination of treatment modalities increases treatment-related morbidities. Landoni et al. reported that higher short-term and long-term complications occurred in the surgery plus adjuvant radiotherapy group than in the primary radiotherapy group [5]. In addition, a recent retrospective study using PSM reported a higher incidence of grade 3 genitourinary complications in early cervical cancer patients with radical hysterectomy followed by tailored adjuvant therapy than with definitive chemoradiotherapy [6]. In addition, previous studies did not use advanced radiotherapy techniques, such as MRI-guided brachytherapy. MRI-guided brachytherapy can reduce toxicity $[14,19]$ and may lead to more favorable benefit in terms of toxicity with definitive chemoradiotherapy than with surgery followed by adjuvant therapy.

The presence of pelvic nodal metastasis is a major indication of adjuvant therapy and affects the prognosis of patients with cervical cancer $[8,20,21]$. The revised FIGO staging reflected the lymph node status. Nevertheless, there is a lack of consensus regarding the most appropriate treatment modality for early cervical cancer presenting with pelvic nodal involvement on imaging. Carlson et al. analyzed the patterns of selecting therapy for patients with early-stage cervical cancer using the Surveillance, Epidemiology and End Results database from 1983 to 2009 [18]. They found that 33.1\% of 10,933 women with early cervical cancer continue to undergo adjuvant radiotherapy after surgery. Thus, to avoid unplanned combined modality treatment, they suggested that further effort is needed to identify the pretreatment risk stratification, particularly pretreatment nodal involvement. Radiotherapy was recommended as the initial treatment suggested for patients with risk factors. To our knowledge, this is the first report comparing the oncologic outcomes of definitive radiotherapy and surgery, focusing on stage IIIC1 patients according to the revised 2018 FIGO guidelines.

Imaging and surgical approach were the available options for pretreatment evaluation of the pelvic nodal status. The revised FIGO staging allows both radiologic and pathologic assessment [22]. MRI detects lymph node metastasis based on the measurement of node size and/or morphology. A specificity of $97 \%$ is reported when nodes are defined as metastatic in cases 
of short-axis larger than $1 \mathrm{~cm}$ [23]. In early cervical cancer, the positive predictive value and accuracy of MRI for detecting lymph node metastasis were reportedly $51-76 \%$ and $67-76 \%[7,24]$. Lee et al. proposed a treatment decision model based on pretreatment MRI findings [25]. Applying MRI-based treatment selection strategy to their cohort, 86 out of 254 were selected for definitive chemoradiotherapy instead of surgery. This change resulted in fewer patients requiring tri-modality therapy $(30.3 \%$ vs. 9.8\%). PET-CT provides functional, metabolism-based information, and it is considered more accurate for the detection of nodal metastasis and unexpected metastasis [26]. Previous studies reported the positive predictive value and accuracy of PETCT for the detection of nodal involvement to be $47-78.2 \%$ and $65-98 \%$, respectively $[7,26,27]$.

Surgical staging can also provide lymph node status before radical surgery. Sentinel node biopsy is known to have the highest diagnostic accuracy to detect pelvic node in early cervical cancer. A meta-analysis and a recent study showed that it had sensitivity of $94-96.4 \%$ and negative predictive value of $91-100 \%[28,29]$. Though there remain some controversies, this method is used as an alternative procedure to replace unnecessary complete pelvic lymphadenectomy with radical surgery for early cervical cancer [30]. Marnitz et al. suggested laparoscopic staging for preoperative staging to avoid tri-modality treatment in early cervical cancer [31]. If lymph node metastasis was detected in frozen biopsy via nodal dissection, patients were scheduled to receive definitive chemoradiotherapy instead of hysterectomy. This strategy can reduce the proportion of patients receiving tri-modality treatment by $9.9 \%$. However, pretreatment laparoscopic surgical staging was associated with complications. Kim et al. found that patients with pretreatment laparoscopic surgical staging with tailored radiotherapy were more likely to suffer from prolonged lower extremity high edema compared with patients who underwent primary radiotherapy in early cervical cancer (69\% vs. $11.6 \% ; 77.3$ months vs. 9.4 months) [32]. In addition, surgical staging is likely to increase the cost and delay the start of the treatment due to time intervals between the surgical procedure and radiotherapy. Conversely, MRI is already widely used to assess the local extent of a tumor in the initial evaluation itself, and thus, the treatment decision to use the pretreatment is easy to use and more cost effective [33]. Thus, the strategy of treatment decision using pretreatment imaging evaluations instead of surgical staging may have some advantages.

This study has several limitations. First, it was a retrospective study that may have inherent bias and heterogeneity of clinicopathological parameters between the two groups. PSM was performed to decrease the effect of potential confounding factors on outcomes. Second, the authors did not measure the size of nodal metastasis that could affect survival based on recent studies [20,34]. This could not be addressed in PSM process either. Finally, treatment-related toxicity could not be assessed because of the retrospective design, and therefore, the authors focused on oncologic outcomes as well as patterns of failure. Despite these limitations, the current study has several strengths. Each treatment was administered consistently. Treatment modality was determined by the policy of each institution and not by clinical factors, such as tumor size, age, and medical co-morbidities. To our knowledge, the current study is the first to compare definitive chemoradiotherapy and radical hysterectomy in early cervical cancer with pelvic nodal involvement confirmed on pretreatment imaging.

\section{Conclusions}

There were no significant differences in survivals and patterns of failure between definitive chemoradiotherapy and surgery followed by tailored adjuvant therapy for early-stage cervical cancer patients with pelvic nodal metastasis on pretreatment imaging studies. In addition, $88.7 \%$ of women with hysterectomy eventually required adjuvant radiotherapy with or without chemotherapy. Based on these findings, the authors suggest that definitive chemoradiotherapy could be employed for earlystage cervical cancer with radiologic pelvic nodal metastasis to avoid excessive complications resulting from unplanned combined modality therapy without compromising oncologic outcomes.

\section{Abbreviations}

OS: Overall survival; MRI: Magnetic resonance imaging; PET-CT: Positron emission tomography-Computed tomography (PET$\mathrm{CT}$ ); CT: Computed tomography; DFS: Disease-free survival; PSM: Propensity score matching

\section{Declarations}




\section{Ethics approval and consent to participate}

This prospective study was performed under approval of Ethical Committee of Asan Medical Center and National Cancer Center (2016-1349). The informed consent was waived because of the retrospective nature of this study.

\section{Consent for publication}

Not applicable

\section{Availability of data and materials}

The datasets used and/or analyzed during this study are available from the corresponding author on reasonable request.

\section{Competing interests}

The authors declare that they have no competing interests

\section{Funding}

There was no funding for this study.

\section{Authors' contributions}

YSK and JYK contributed to the conception and design of the study. JP and YJK participated in data acquisition and analysis and literature research and drafted the manuscript. MKS participated in statistical analysis. SYP and JHN revised the manuscript. All authors read and approved the final manuscript.

\section{Acknowledgement}

We thank MD Bo Ram Ha for data curation and PhD Jungnam Joo for statistical analysis.

\section{Authors' information}

${ }^{a}$ Department of Radiation Oncology, Kyungpook National University Chilgok Hospital, Daegu, Republic of Korea. ${ }^{b}$ Department of Radiation Oncology, Proton Therapy Center, National Cancer Center, Goyang-si, Gyeonggi-do, Republic of Korea. 'Biometrics Research Branch and Biostatistics Collaboration Unit, National Cancer Center, Goyang-si, Gyeonggi-do, Republic of Korea.

${ }^{d}$ Health Insurance Policy Research Institute, National Health Insurance Service, 199, Hyeoksin-ro, Wonju-si, Gangwon-do, Republic of Korea (Current affiliation). 'Department of Obstetrics and Gynecology, Asan Medical Center, University of Ulsan, College of Medicine, 88, Olympic-ro 43-gil, Songpa-gu, Seoul 05505, Republic of Korea. ${ }^{\mathrm{f} C e n t e r ~ f o r ~ U t e r i n e ~ C a n c e r, ~ N a t i o n a l ~}$ Cancer Center, Goyang-si, Gyeonggi-do, Republic of Korea. ${ }^{9}$ Department of Radiation Oncology, Asan Medical Center, University of Ulsan, College of Medicine, 88, Olympic-ro 43-gil, Songpa-gu, Seoul 05505, Republic of Korea.

\section{References}

1. Bhatla N, Aoki D, Sharma DN, Sankaranarayanan R. Cancer of the cervix uteri. Int J Gynaecol Obstet. 2018;143 (Suppl 2):22-36.

2. Frumovitz M, Sun CC, Schover LR, Munsell MF, Jhingran A, Wharton JT, et al. Quality of life and sexual functioning in cervical cancer survivors. J Clin Oncol. 2005;23(30):7428-36.

3. Trifiletti DM, Swisher-McClure S, Showalter TN, Hegarty SE, Grover S. Postoperative chemoradiation therapy in high-risk cervical cancer: re-evaluating the findings of gynecologic oncology group study 109 in a large, population-based cohort. Int J Radiat Oncol Biol Phys. 2015;93(5):1032-44. 
4. Peters WA, 3rd, Liu PY, Barrett RJ, 2nd, Stock RJ, Monk BJ, Berek JS, et al. Concurrent chemotherapy and pelvic radiation therapy compared with pelvic radiation therapy alone as adjuvant therapy after radical surgery in high-risk early-stage cancer of the cervix. J Clin Oncol. 2000;18(8):1606-13.

5. Landoni F, Maneo A, Colombo A, Placa F, Milani R, Perego P, et al. Randomised study of radical surgery versus radiotherapy for stage Ib-lla cervical cancer. Lancet. 1997;350(9077):535-40.

6. Kong TW, Lee JD, Son JH, Paek J, Chun M, Chang SJ, et al. Treatment outcomes in patients with FIGO stage IB-IIA cervical cancer and a focally disrupted cervical stromal ring on magnetic resonance imaging: a propensity score matching study. Gynecol Oncol. 2016;143(1):77-82.

7. Chung HH, Kang KW, Cho JY, Kim JW, Park NH, Song YS, et al. Role of magnetic resonance imaging and positron emission tomography/computed tomography in preoperative lymph node detection of uterine cervical cancer. Am J Obstet Gynecol. 2010;203(2):156 e1-5.

8. Kidd EA, Siegel BA, Dehdashti F, Rader JS, Mutch DG, Powell MA, et al. Lymph node staging by positron emission tomography in cervical cancer: relationship to prognosis. J Clin Oncol. 2010;28(12):2108-13.

9. Wright JD, Dehdashti F, Herzog TJ, Mutch DG, Huettner PC, Rader JS, et al. Preoperative lymph node staging of early-stage cervical carcinoma by $\left[{ }^{18} \mathrm{~F}\right]-$ fluoro-2-deoxy-D-glucose-positron emission tomography. Cancer. 2005;104(11):2484-91.

10. Liu Y, Liu H, Bai X, Ye Z, Sun H, Bai R, et al. Differentiation of metastatic from non-metastatic lymph nodes in patients with uterine cervical cancer using diffusion-weighted imaging. Gynecol Oncol. 2011;122(1):19-24.

11. Sironi S, Buda A, Picchio M, Perego P, Moreni R, Pellegrino A, et al. Lymph node metastasis in patients with clinical earlystage cervical cancer: detection with integrated FDG PET/CT. Radiology. 2006;238(1):272-9.

12. Kim JH, Kim JY, Yoon MS, Kim YS, Lee JH, Kim HJ, et al. Prophylactic irradiation of para-aortic lymph nodes for patients with locally advanced cervical cancers with and without high CA9 expression (KROG 07-01): a randomized, open-label, multicenter, phase 2 trial. Radiother Oncol. 2016;120(3):383-9.

13. Kim YJ, Kim JY, Kim TH, Lim YK, Yoon MG, Joo JN, et al. Dosimetric evaluation of magnetic resonance imaging-based intracavitary brachytherapy for cervical cancer. Technol Cancer Res Treat. 2014;13(3):243-51.

14. Kim YJ, Kim JY, Kim Y, Lim YK, Jeong J, Jeong C, et al. Magnetic resonance image-guided brachytherapy for cervical cancer : prognostic factors for survival. Strahlenther Onkol. 2016;192(12):922-30.

15. Dimopoulos JC, Petrow P, Tanderup K, Petric P, Berger D, Kirisits C, et al. Recommendations from Gynaecological (GYN) GEC-ESTRO Working Group (IV): Basic principles and parameters for MR imaging within the frame of image based adaptive cervix cancer brachytherapy. Radiother Oncol. 2012;103(1):113-22.

16. Zivanovic O, Alektiar KM, Sonoda Y, Zhou Q, lasonos A, Tew WP, et al. Treatment patterns of FIGO Stage IB2 cervical cancer: a single-institution experience of radical hysterectomy with individualized postoperative therapy and definitive radiation therapy. Gynecol Oncol. 2008;111(2):265-70.

17. Gupta S, Maheshwari A, Parab P, Mahantshetty U, Hawaldar R, Sastri Chopra S, et al. Neoadjuvant chemotherapy followed by radical surgery versus concomitant chemotherapy and radiotherapy in patients with stage IB2, IIA, or IIB squamous cervical cancer: a randomized controlled trial. J Clin Oncol. 2018;36(16):1548-55.

18. Carlson JA, Rusthoven C, DeWitt PE, Davidson SA, Schefter TE, Fisher CM. Are we appropriately selecting therapy for patients with cervical cancer? Longitudinal patterns-of-care analysis for stage IB-IIB cervical cancer. Int J Radiat Oncol Biol Phys. 2014;90(4):786-93.

19. Potter R, Georg P, Dimopoulos JC, Grimm M, Berger D, Nesvacil N, et al. Clinical outcome of protocol based image (MRI) guided adaptive brachytherapy combined with 3D conformal radiotherapy with or without chemotherapy in patients with locally advanced cervical cancer. Radiother Oncol. 2011;100(1):116-23.

20. Song S, Kim JY, Kim YJ, Yoo HJ, Kim SH, Kim SK, et al. The size of the metastatic lymph node is an independent prognostic factor for the patients with cervical cancer treated by definitive radiotherapy. Radiother Oncol. 2013;108(1):16873. 
21. Rose PG, Java J, Whitney CW, Stehman FB, Lanciano R, Thomas GM, et al. Nomograms predicting progression-free survival, overall survival, and pelvic recurrence in locally advanced cervical cancer developed from an analysis of identifiable prognostic factors in patients from nrg oncology/gynecologic oncology group randomized trials of chemoradiotherapy. J Clin Oncol. 2015;33(19):2136-42.

22. Bhatla N, Berek JS, Cuello Fredes M, Denny LA, Grenman S, Karunaratne K, et al. Revised FIGO staging for carcinoma of the cervix uteri. Int J Gynaecol Obstet. 2019;145(1):129-35.

23. Rockall AG, Sohaib SA, Harisinghani MG, Babar SA, Singh N, Jeyarajah AR, et al. Diagnostic performance of nanoparticleenhanced magnetic resonance imaging in the diagnosis of lymph node metastases in patients with endometrial and cervical cancer. J Clin Oncol. 2005;23(12):2813-21.

24. Sarabhai T, Schaarschmidt BM, Wetter A, Kirchner J, Aktas B, Forsting M, et al. Comparison of ${ }^{18}$ F-FDG PET/MRI and MRI for pre-therapeutic tumor staging of patients with primary cancer of the uterine cervix. Eur J Nucl Med Mol Imaging. 2018;45(1):67-76.

25. Lee JY, Youm J, Kim JW, Kim K, Kim HJ, Cho JY, et al. An alternative triage strategy based on preoperative MRI for avoiding trimodality therapy in stage IB cervical cancer. Cancer Res Treat. 2016;48(1):259-65.

26. Lv K, Guo HM, Lu YJ, Wu ZX, Zhang K, Han JK. Role of 18F-FDG PET/CT in detecting pelvic lymph-node metastases in patients with early-stage uterine cervical cancer: comparison with MRI findings. Nucl Med Commun. 2014;35(12):1204-11.

27. Signorelli M, Guerra L, Montanelli L, Crivellaro C, Buda A, Dell'Anna T, et al. Preoperative staging of cervical cancer: is 18FDG-PET/CT really effective in patients with early stage disease? Gynecol Oncol. 2011;123(2):236-40.

28. Tax C, Rovers MM, de Graaf C, Zusterzeel PL, Bekkers RL. The sentinel node procedure in early stage cervical cancer, taking the next step; a diagnostic review. Gynecol Oncol. 2015;139(3):559-67.

29. Salvo G, Ramirez PT, Levenback CF, Munsell MF, Euscher ED, Soliman PT, et al. Sensitivity and negative predictive value for sentinel lymph node biopsy in women with early-stage cervical cancer. Gynecol Oncol. 2017;145(1):96-101.

30. Lennox GK, Covens A. Can sentinel lymph node biopsy replace pelvic lymphadenectomy for early cervical cancer? Gynecol Oncol. 2017;144(1):16-20.

31. Marnitz S, Kohler C, Affonso RJ, Schneider A, Chiantera V, Tsounoda A, et al. Validity of laparoscopic staging to avoid adjuvant chemoradiation following radical surgery in patients with early cervical cancer. Oncology. 2012;83(6):346-53.

32. Kim SI, Lim MC, Lee JS, Kim YJ, Seo SS, Kang S, et al. Comparison of lower extremity edema in locally advanced cervical cancer: pretreatment laparoscopic surgical staging with tailored radiotherapy versus primary radiotherapy. Ann Surg Oncol. 2016;23(1):203-10.

33. Lee JY, Kwon JS, Cohn DE, Kim Y, Smith B, Lee TJ, et al. Treatment strategies for stage IB cervical cancer: a costeffectiveness analysis from Korean, Canadian and U.S. perspectives. Gynecol Oncol. 2016;140(1):83-9.

34. Park SH, Cheon H, Chong GO, Jeong SY, Lee JE, Kang MK, et al. Prognostic significance of residual lymph node status after definitive chemoradiotherapy in patients with node-positive cervical cancer. Gynecol Oncol. 2018;148(3):449-55.

\section{Figures}


A

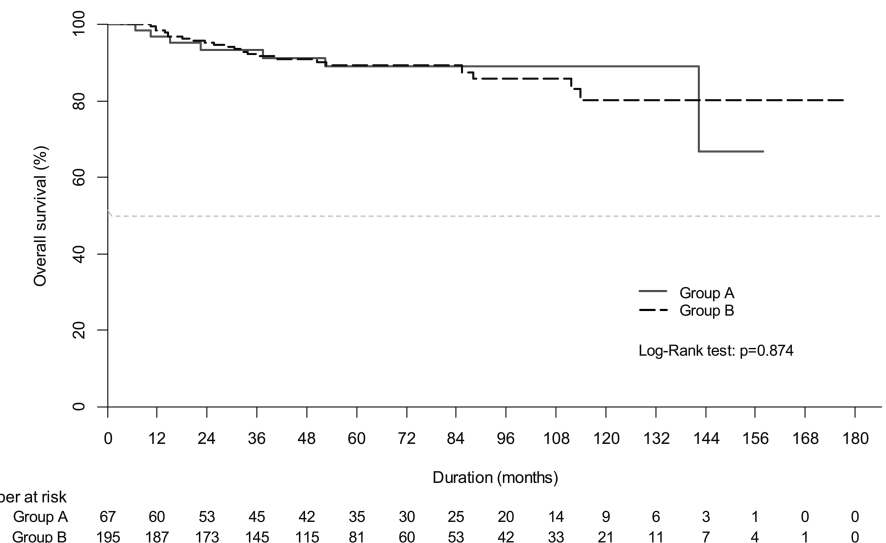

B

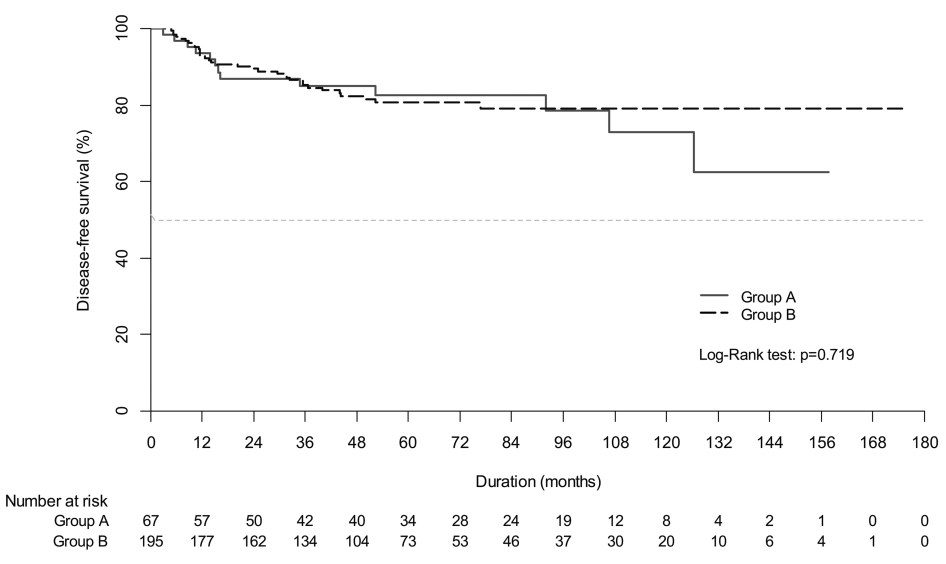

Figure 1

Kaplan-Meier estimates of (A) overall survival curves, and (B) disease free survival curves between definitive chemoradiotherapy (group A) and up front radical hysterectomy followed by tailored adjuvant therapy (group B) in entire cohort.

A

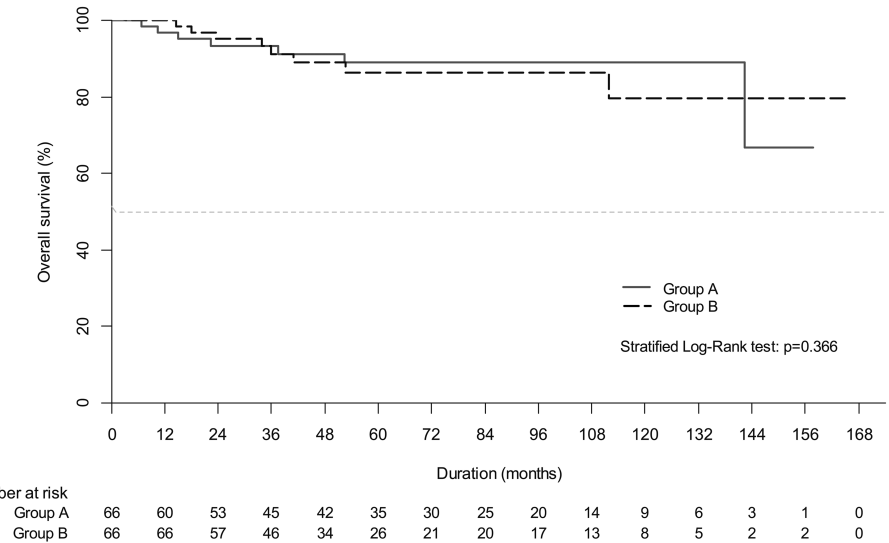

B

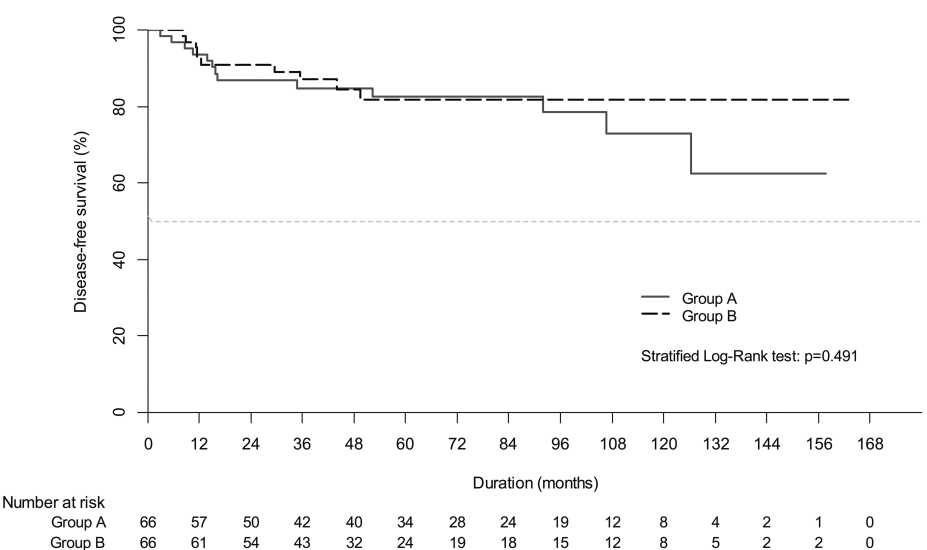

\section{Figure 2}

Kaplan-Meier estimates of (A) overall survival curves, and (B) disease free survival curves between definitive chemoradiotherapy (group A) and up front radical hysterectomy followed by tailored adjuvant therapy (group B) in propensity score matching cohort. 